\title{
Assessing the Impacts of Regional Characteristics on the Location of Manufacturing Facilities: A Review of Recent Methods and Findings
}

by F.J. Calzonetti* and R.C. Hemphill

Economics and Law Section,

Environmental Assessment and Information Sciences Division,

Argonne National Laboratory, 9700 South Cass Avenue, Argonne. Illinois 60439

July 1990 (printed January 1992)

Work sponsored by United States Department of Energy,

Office of Civilian Radioactive Waste Management

"Calzonetti is affiliated with the Department of Geology and Geography, College of Arts and Sclences, West Virgina University, Morgantown. 


\section{CONTENTS}

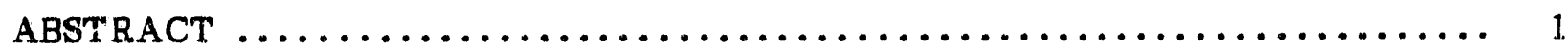

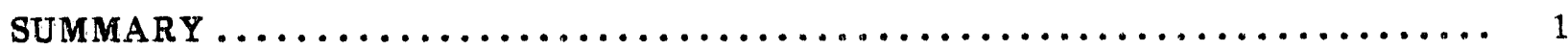

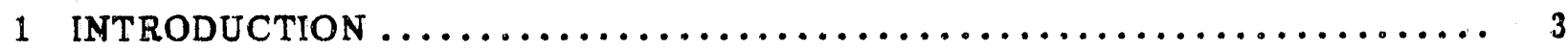

1.1 Purpose of and Rationale for This Review .................. 3

1.2 Categorization of Research Methods Used in Previous Studies .......... 4

1.3 Sources of Industrial Data Used for Previous Studies .............. 5

2 REVIEW OF METHODS FOR DETERMINING THE FACTORS AFFECTING INDUSTRIAL LOCATION DECISIONS $\ldots \ldots \ldots \ldots \ldots \ldots \ldots \ldots \ldots \ldots \ldots \ldots \ldots \ldots 7$

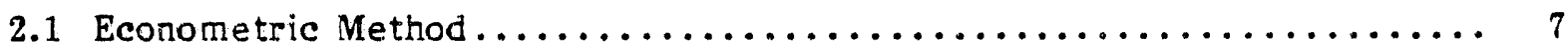

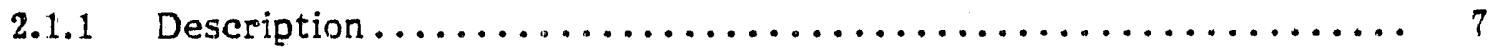

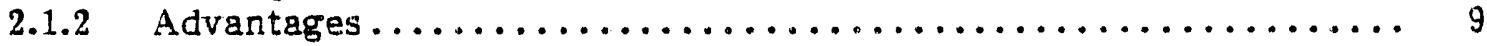

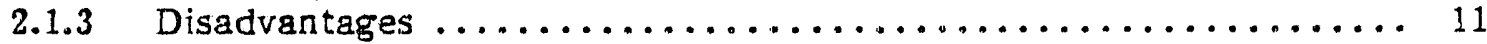

2.2 Survey Factor-Ranking Method......................... 12

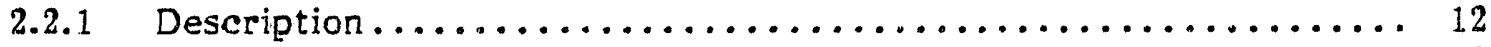

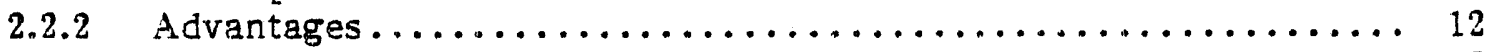

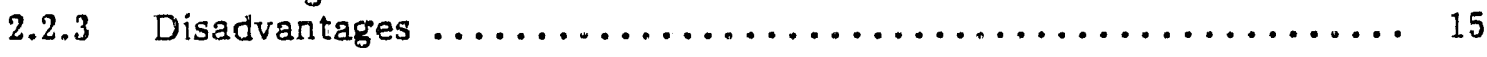

3 FINDINGS IN THE LITERATURE $\ldots \ldots \ldots \ldots \ldots \ldots \ldots \ldots \ldots \ldots \ldots \ldots \ldots \ldots$

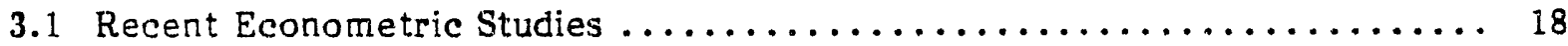

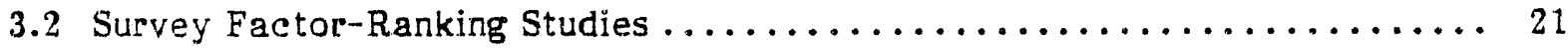

4 FACTORS INFLUENCING INDUSTRIAL LOCATION

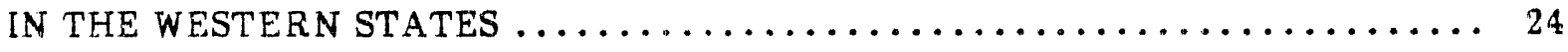

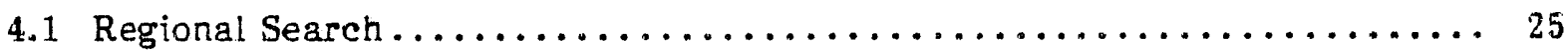

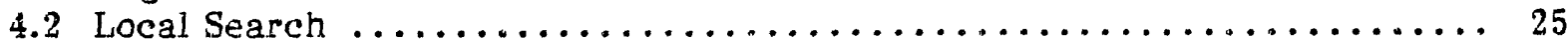

5 IMPLICATIONS FOR RESEARCH ON PERCEPTION-BASED IMPACTS ...... 30

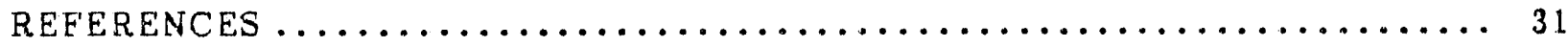

\section{TABLES}

1 Significance of Location Factors According to Questionnaire and

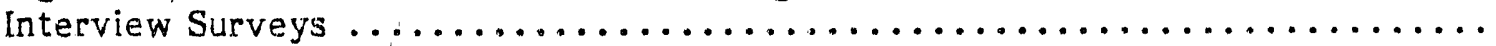

2 Ranking of Factors Important in a Regional Search According to

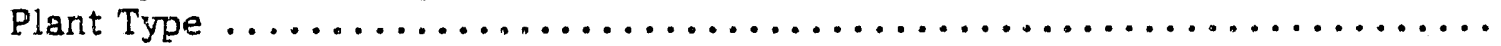

3 Ranking of Factors Important in a Local Search According to

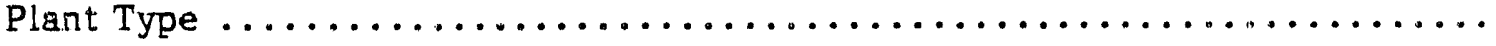

4 Ranking of Factors Important in a Local Search by Single-Flant

Establishments According to Region 


\title{
ASSESSING THE IMPACTS OF REGIONAL CHARACTERISTICS ON THE LOCATION OF MANUFACTURING FACILITIES: A REVIEW OF RECENT METHODS AND FINDINGS
}

by

\author{
F.J. Calzonetti and R.C. Hemphill
}

\begin{abstract}
This report gives federal agencies background information to help them assess the impacts that siting a nuclear-waste storage facility could have on industries making location decisions in various regions of influence. It reviews two major research methods used to analyze reasons for location choices: economic-based or econometric methods and survey-based factor-ranking methods. It summarizes the results of studies that have used these methods, identifying and ranking factors shown to be importent to industries making location decisions throughout the nation and in western states. Neither economic-based nor survey-based studies have shown the public's perceptions of a region to be an important determinant in the selection of new manufacturing sites, although consideration of the level of amenities is gaining importance in the West. In general, available studies are inconclusive with respect to the extent to which perceptions about hazards play a role in the location of manufacturing facilities in any region of the nation.
\end{abstract}

\section{SUMMARY}

The purposes of this report are to (1) summarize the methods researchers of ten use to evaluate the factors influencing industrial location decisions and (2) identify those factors that have been most influential in such decisions. The report is intended to provide the U.S. Department of Energy's Office of Civilian Radioactive Waste Management with better information to assess the potential impacts that the location of a nuclear waste storage facility could have on industrial location decision making in regions of influence. Since the literature on industrial location is extensive, one way to approach it, as proposed by Blair and Premus (1987), is to eategorize studies into those that use econometric research methods and those that use survey-based factor-ranking research methods.

This report describes both of these methods and examines their respective strengths and weaknesses. First, however, it considers a problem that of ten dictates research design and that is universal to all who undertake industrial studies: the problem of obtaining a listing of new plants. 
Following a review of econometric and survey-based factor methods, this report presents a summary of findings from studies that have used these two methods to identify factors important in industrial location decisions. Findings reveal that in neither type of study has the public's perceived risk of the region's hazardous facilities been an important determinant in the selection of new manufacturing sites. However, little research has been conducted to determine whether the location of such hazardous facilities influences either industrial location decisions or the distribution of industry.

Finally, this repor: summarizes those factors most important in influencing firms to locate in the United States and in the western states in particular. Among the conclusions are that (1) many plants are located without any prior search having been undertaken, especially a search that compares multistate regions of the country, and (2) one of the important reasons for selecting western regions as a site for new manufacturing facilities is a community's amenities and its liveability. At present, too few studies exist to make any general conclusions regarding the role that hazardous facilities play in the perceptions of amenities. 


\section{INTRODUCTION}

\subsection{PURPOSE OF AND RATIONALE FOR THIS REVIEW}

This report addresses the effects that public perceptions of hazardous facilities could have on decisions to locate industrial facilities in different regions of the United States. This issue has become an area of concern in recent years, because studies assessing socioeconomic impacts from hazardous energy projects have been devoting more attention to perception-based impacts.* For example, the ramifications of perceived risk and other negative imagery have been discussed in particular in two relatively recent reports. One discusses the potential socioeconomic impacts that could result from the siting of a permanent radioactive waste repository in Nevada; the other discusses the potential effects from siting a monitored retrievable storage (MRS) facility in Tennessee. The first report is a summary of an aggressive study sponsored by the state of Nevada (Mountain West Research 1989). A thorough discussion of the factors under consideration within the state of Tennessee is included in CBER (1985).

According to Mountain West Research, the State of Nevada's interim report on its research findings separates socioeconomic impacts into two eategories: standard impacts and special effects. Special effects include all perception-based impacts; standard impacts include what is typically covered in the framework of an environmental impact statement. The Nevada report then devotes the majority of its discussion to special effects. The researchers claimed that they focused on these types of socioeconomic impacts because the repository's hazardous characteristics could affect Nevada in two ways: by diminishing the quality of life for the Nevada residents and by reducing the economic base of the state.

The report's discussion of the potential impacts from the stigma, image problems, and perceptions of risk concentrates on the results of numerous surveys and interviews conducted over the past three years. Special mention is made of how a deteriorating image of Nevada could influence businesses to locate elsewhere, thus negatively affecting Nevada's economy.

The Nevada report discusses four different survey methods used to determine the potential of each of the impacts mentioned above:

1. A general risk perception survey was conducted using national and Nevada samples to assess the risks people associate with nuclear energy and its consequent wastes.

2. A national survey was conducted to determine the relative attractiveness of Las Vegas as a choice for siting housing and

\footnotetext{
*As described by Hemphill et al. (1990), the term "perception-based impacts" includes risk perception, stigma, and any other negative imagery related to the nuisance factor of a hazardous waste facility.
} 
businesses and to determine the sensitivity of opinions on attractiveness to the introduction of nuclear wastes.

3. Telephone surveys were conducted to determine the images associated with Nevada and Las Vegas and to assess the implications of such imagery on economic behavior.

4. Special surveys were conducted to assess the impacts of the repository on convention planning, tourism, business location decisions, and economic development potential.

It is also likely that any organized opposition to an MRS siting effort would rely on showing negative impacts in these four areas. For example, a frequently quoted report on the potential socioeconomic impacts from siting an MRS in Tennessee (CBER 1988) concentrates on the economic effects of changing perceptions and how these changes influence business location.

The studies indicate that substantial impacts to major sectors of an economy may occur in any area where a radioactive waste storage facility is located. These economic impacts are a result of the public's image of radioactive waste, whether that image is based on perceptions of risk or on a stigma attached to the area surrounding such a facility. In other words, the studies hypothesize that there is a risk to any region hosting a radioactive-waste storage facility because, among other things, such a facility could make the region less attractive to industry. Those responsible for determining the location of new (or the expansion of existing) industrial facilities might tend to avoid considering regions hosting nuclear waste facilities. The impact would be to reduce the region's employment and tax revenues compared with what they might have been without the repository.

In response to the increased concern about the issues reflected in these reports, the U.S. Department of Energy's Office of Civilian Radioactive Waste Management needs information to assess the potential impacts of a nuclear waste facility on industrial location in any region. To provide this information, this report (1) reviews the methods that have been used to investigate factors influencing industrial location decisions and (2) summarizes the factors that have been shown to affect industrial location, both nationwide and in the western states specifically. The review shows that the issue of risk perception was not explicitly considered in any of the past studies investigating the location decision-making process used by manufacturing facilities. However, many of the past studies did consider the importance of a region's amenities and disamenities with respect to making decisions on where to locate new (or expand existing) manufacturing facilities. From the results of these studies, inferences can be made about the importance of a hypothesized nuisance, such as a nuclear waste repository, as a factor in location decisions.

\subsection{CATEGORIZATION OF RESEARCH METHODS USED IN PREVIOUS STUDIES}

This report categorizes the decision-making methods used to determine location into two types -- the econometric research method and the survey-based factor-ranking 
method - and summarizes the literature that provides the context for these two methods. The factors affecting industrial location nationwide are then reviewed, using published studies that emphasized these methods in their research. Finally, factors that have been shown to influence industrial location in the western states are summarized, using a study conducted by the West Virginia University and funded by the Economic Development Administration.

Studies of industrial location can be traced to the nineteenth century and have a long tradition in economics and geography. Generally, such studies can be classified according to two types: theoretical studies and empirical studies. Theoretical studies aim to provide a general theory for the location of industry. These studies originated with the work of Weber (1909), and their number has grown significantly throughout this century. Theoretical studies are of ten divided into two types based on their approach. The least-cost approach focuses on developing theories to explain how industrial locations are selected to minimize total costs. The locational interdependence approach focuses on developing theories to explain how industrial locatiors are selected to control a market area and to maximize sales. Other studies, such as those by Greenhut (1956) and Smith (1966), synthesize these two theoretical approaches. Although theoretical studies are not the emphasis of this report and thus will not be discussed further here, the interested reader can find a good review of them in Smith (1981).

Empirical studies are the most pervasive, extending across several disciplines and into the popular literature. In this report, the focus is on empirical studies dealing with manufacturing industries. One way to organize this literature is to use the categories developed by Blair and Premus (1987), who classify empirical studies into two types: econometric studies and survey studies. An alternative approach is suggested by Bartels, Nicol, and Duijn (1982), who classify studies as either "macro-studies" or "micro-studies," according to the level of aggregation of the data. According to Bartels, Nicol, and Duijn, macro-studies are those that use aggregate data normally found at the national or state level. Most macro-studies in the industrial location literature employ econometric methods of analysis. By contrast, micro-studies use data that have been collected on individual units, such as manufacturing facilities or firms. Most micro-studies employ survey-based methods, in which information is collected froin questionnaires or through interviews. Once the data have been collected, the researcher may use econometric methods, classification procedures, or descriptive statistics to analyze the data.

This report discusses both econometric studies and survey-based studies, with the understanding that there is not always a clear separation between the two approaches; i.e., econometric studies often involve macroeconomic ("macro") data and some microeconomic ("micro") data, and many survey-based studies involve econometric analysis.

\subsection{SOURCES OF INDUSTRIAL DATA USED FOR PREVIOUS STUDIES}

Before econometric methods and survey-based factor-ranking methods are reviewed here, one of the major problems in industrial analysis needs to be discussed: the lack of a comprehensive source of plant-level data. A preferred source is the U.S. Bureau of the Census publication, County Business Patterns, which is updated and 
published each year (unlike the quinquennial economic censuses such as the Census of Manufactures). This report tabulates data obtained from the Bureau of Labor Statistics on the total number of establishments for each Standard Industrial Classification (SIC) code across nine employment categories." It is considered to be a "universe" file. However, it lists only the total number of establishments from year to year; therefore, it can be used only as a means to determine changes in the number of establishments each year. Plants open and close, but the report does not directly measure these plant "births" or closures. Furthermore, County Business Patterns does not list plant names and addresses and thus cannot be used as a source from which to draw samples.

Many industrial researchers who need information on plant births or the names and addresses of plants purchase files from Dun and Bradstreet Corp. (D\&B), which maintains the Market Identifiers File, a file that provides detailed information on approximately 5.5 million businesses. Dun and Bradstreet, as well as others, claim that this file is the most comprehensive file on business. However, recent reviews have challenged these elaims. For example, Schwartz (1987) obtained a random sample of 1378 New Jersey "new" tirms from the Market identifiers File but found that only $35 \%$ of the firms in this sample were actually new businesses. Furthermore, because local relocations and acquisitions are of ten considered "new" firms in the Market Identifiers File, the statistics are inflated and unreliable. This point is important because many researchers use the D\&B Market ldentifiers File both in econometric studies (to identify the number of new plants that have opuned in an area over a period of time) and as a source of mailing lists for survey research projects.

Other sources of data include state manufacturing directories and state employment security administration files. However, many state industriai directories do not include the date of plant establishment, and the comprehensiveness of these directories varies considerably. State employment security data (ES-202 files) are very difficult to obtain since they contain confidential iniormation about particular establishments that cannot be publicly released.

*The Standard Industrial Classification (SIC) system is the classification standard underlying all establishment-based federal economic statistics that are classified by type of industry. The SIC system covers the entire field of economic activities and defines industries in accordance with the composition and structure of the economy. This classification system is used in any comprehensive study that compares industries in the U.S. economy. 


\section{REVIEW OF METHODS FOR DETERMINING THE FACTORS AFPECTING INDUSTRLAL LOCATION DECISIONS}

This section of the report examines the econometric and the survey-based factor-ranking methods for determining the factors affecting industrial location decisions. In addition to describing these methods, literature is cited that shows how researchers have used these methods.

\subsection{ECONOMETRIC METHOD}

As discussed in the introduction, the econometric method for analyzing the basis on which the locations for manufacturing facilities are chusen usually involves the statistical analysis of aggregate data (macro-level data). This method of explaining location decision making assumes that patterns can be identified by observing large groups of facilities nationwide. This section of the report describes the econometric approach and discusses the advantages and disadvantages of its implementation.

\subsubsection{Description}

According to Blair and Premus (1987), econometric studies examine where firms locate or investigate other factors that indicate changes in or levels of industrial activity, such as employment in a particular area (standard metropolitan statistical area or SMSA, county, state, or multistate region). These studies are sometimes classified into two types: ones that evaluate industry location in an interstate or intermetropolitan setting and ones that evaluate industry location in an incrametropolitan setting. As mentioned previously, a problem faced by all industrial location researchers is that there is no single comprehensive source of data listing the number of new establishments that have opened or closed in an area over a particular period. Thus, if the researcher wishes to examine establishment trends by industry, only changes in the number of establishments across periods can be examined by using census data. Actual new-firm formation data must be derived from alternative sources.

As a result, many industrial location researchers model industrial growth by considering factors other than the number of establishments -- factors ch as employment, value added, or investment. As discussed by Bartik (1.985), two models can be used. One is the disequilibrium-adjustment model, in which "the change in the dependent variable over the period is related to levels of independent variables at the beginning of the period" (Plaut and Pluta 1983, p. 102). This model is based on the assumption that the differences in industrial profitability at the beginning of the period are large enough to cause differences in the rate of industrial growth. According to Bartik (1988), changes in economic activity in an area can be expressed as a function of levels of the area's characteristics, as follows:

$$
A_{i t}-A_{i t-1}=B^{\prime} X_{i t}-A_{i t-1}+e_{i t}
$$


where:

$$
\begin{aligned}
A_{i t} & =\text { the activity level of area } i \text { at time } t \\
B & =\text { coefficient for } X \\
X_{i t} & =\text { a vector of observed characteristics at area } i \text { for time period } t \text {, and } \\
e_{i t} & =\text { the disturbance term. }
\end{aligned}
$$

Ordinary least-squares regression is typically used to estimate the coefficients. (As in any least-squares regression analysis, the ability of the model to provide an acceptable estimate of the coefficients is dependent on the exhibited strength of the stochastic assumptions regarding the error term.) As is discussed later, Plaut and Pluta (1983) use four classes of independent variables in predicting three measures of economic activity in different states. The dependent variables used are value added, employment, and capital stock (all expressed as percent change) over the 1967-1972 and 1972-1977 time periods.

This model has also been used with micro-level data (Carlton 1979, 1983; Bartik 1985). Carlton (1973) uses this model to evaluate the birth of new manufacturing plants (new firms and branch plants) for selected industries across SMSAs. Micro-level data on plants are related to the economic characteristics of the SMSA. Thus this approact is based on the assumption that the birth of new manufacturing plants over a particular time period is related to the economic activities in an SMSA.

In contrast to this "changes/levels" model is the "changes/changes" model, in which growth in a region is a result of changes in an area's characteristics. This model expressed as follows (Bartik 1985):

$$
\left.A_{i t}-A_{i t-1}=\lambda \underline{B}_{i t}-X_{i t-1}\right)+(1-\lambda)\left(A_{i t-1}-A_{i t-2}\right)+e_{i t}-e_{i t-1}
$$

Newman (1983) provides an illustration of this model, in which the dependent variable is a measure of change in total employment across two overlapping time periods, 1957-1965 and 1965-1973, expressed as follows:

$$
\Delta T E=\left(E_{s i}^{1 / E_{s i}}{ }^{0}\right)-\left(E_{i}^{1} / E_{i}^{0}\right)
$$

where:

$\Delta \mathrm{TE}=$ relative change in total employment,

$E_{s i}{ }^{1}=$ total employment in state $s$ for industry $i$ in the terminal year,

$\mathrm{E}_{\mathrm{si}}{ }^{0}=$ employment in state $\mathrm{s}$ for industry in the initial year, 

$\begin{aligned} & E_{i}{ }^{1}= \text { total employment in the nation for industry } i \text { in the terminal } \\ & \text { year, and }\end{aligned}$

$E_{i}^{0}=$ employment in the nation for industry $i$ in the initial year.

Independent variables in Newman's model are corporate income tax, unionization, and business climate (as expressed by having a right-to-work law).

Bartik (1985) summarizes the advantages and disadvantages of each model. The changes/changes model does not account for the possible correlation between an area's existing fixed effects and the area's observed characteristics. By contrast, the changes/levels model provides estimates of the relative importance of various characteristics based upon these omitted fixed effects. Bartik also notes that the changes/changes model has greater bias because it employs "differencing," which, although it eliminates much of the true variance, does not eliminate measurement error variance in the $X$ variables. Thus, when the independent variables are specified as changes, more noise is present. Because much of the true variance in the $\mathrm{X}$ variabies is eliminated in the changes/changes model, the changes/levels model is like!y to result in estimates with smaller standard errors. Bartik also observes that the changes/levels model requires a smaller amount of data to make estimations than does the changes/changes model, since it requires data on the level of the $\mathrm{X}$ variables for only one time period and on the level of industrial activity for only two time periods. By contrast, the changes/changes model requires data on the $\mathrm{X}$ variables for two time periods and on industrial activity for three time periods.

Many studies in the literature differ on which dependent and independent variables and method of estimation to use. Because of the many approaches used and the different variables being studied, it may appear that there is some confusion about how industrial location theory can be applied. However, the econometric approach has several key advantages that make it a popular method for industrial location analysis. The next few sections discuss the advantages and disadvantages of the econometric method.

\subsubsection{Advantages}

The major advantages of the econometric method are these: (1) the data are easily accessible, (2) the research is relatively inexpensive, (3) one can control and test for the significance of particular variables, and (4) the researcher is evaluating actual behavior using observations within the market.

\subsubsection{Most Data Are Easily Accessible}

One of the most compelling reasons that econometric approaches to the study of industrial location are so popular is that they can be conducted easily. As will be shown later, it is very difficult to obtain micro-level data on specific plant characteristics. Macro-level data, however, are readily accessible at various geographic scales (state, county, SMSA) and thus can be used to evaluate the significance of factors affecting 
industrial growth or decline. The easiest approach is to use U.S. Bureau of the Census data in a cross-sectional analysis using states, counties, or SMSAs as the unit of observation in a changes/changes or changes/levels model. The dependent variable would be some measure of industrial activity, and the independent variables would be the location attributes that the researcher considers influential to industrial activity. An alternative approach is to use the micro-level data with the macro-level data. This approach analyzes information on plant births by region as a function of each region's attributes. This approach, which has been applied by Cariton (1979, 1983), Oster (1979), Bartik (1985), and Schmenner, Huber, and Cook (1987), utilizes plant birth information from $D \& B$.

\subsubsection{Research Is Inexpensive}

It is not very expensive to access data from census files for use in an econometric model. If the researcher wishes to use the number of plant openings as a dependent variable, D\&B's Market Identifiers File, state manufacturing directories, or state employment security commission files will need to be used. The minimum cost for ordering the Market Identifiers File is about $\$ 2000$; however, the researcher of ten has to spend many times that amount to clean up the file so the data are useful for research. Much of the data needed for the independent variables are available from the census files also.

\subsubsection{Significance of Particular Variables Is Tested}

The econometric method is ideally suited for testing the significance of particular variables because it controls for all other identified factors. In this way, the researcher can test for the significance of a minor factor, such as infrastructure or taxes, on industry location - a factor that normally would be overpowered by traditional market and production cost factors. Thus, the method may be useful for testing whether public perception is a significant variable in decisions to locate plants in regions where noxious facilities exist. The method's usefulness, of course, is based on the assumption that perceptions are identified and measured in a manner consistent with that used for the other variables in the data base.

\subsubsection{Conciusions Are Based on Actual Behavior}

Another advantage of using the econometric method to study industrial location is that the researcher is evaluating the actual behavior of the decision maker. The researcher associates the attributes of locations to the locations actually selected. One very useful approach is to obtain data on locations that were considered but rejected as well as data on the locations that were selected. This information is important because most new plants are selected without a location search having been conducted; thus, one cannot datermine if the characteristics of a location had any bearing on the choice. Also, only by studying how decision makers reject one location in favor of another can the presence or significance of a particular variable be evaluated. Schmenner, Huber, 
and Cook (1987) use such information in their two-stage multinomial logit model to determine why manufacturers rejected certain states in favor of others.

\subsubsection{Disadvantages}

The major disadvantages of the econometric method are (1) data constraints, (2) the difficulty of making inferences about individual behavior from ecological information, and (3) the difficulty of interpreting the results.

\subsubsection{Some Data Are Not Accessible}

Although data for many ecolomic variables are available from the census, the data for many of the other variables necessary to conduct this analysis are not easily accessible. For example, since many researchers have difficulty dealing with the market variable, they use surrogates to represent proximity to market. Such surrogates, however, are of ten unsuccessful because it is generally impossible to know the location from which a plant is shipping a product. In an attempt to ascertain the significance of market proximity as a location factor, Wheat (1986) uses various state ratios, which include variables for manufacturing employment, population, and personal income, as well as measures of how far the location is from the manufacturing belto plaist and Pluta (1983, p. 104) measure markets by using a ratio of personal incerpe potential to manufacturing value-added potential, based upon distances from the popilation centroids across states. The assumption is that "manufacturers are expected to locate relatively close to under-served markets to reduce transportation costs and to avoid competition." Population potential may not be a significant factor to manufacturers of specialized components, but it is probably a good measure for some industries, such as printing.

As mentioned previously, industrial researchers find plant-specific details very useful (and many times require them). However, the type of data required depends entirely on what is being explained. For example, if the dependent variable is changes in (or levels of) establishments or employment, having facility-specific data is not as critical. Because some data are readily available whereas other data are not, some researchers tend to focus on those variables for which data are available.

\subsubsection{Conclusions about Individual Behavior Are Inferred}

A general problem with cross-sectional econometric studies is that the conclusions often discuss factors that influence individual decision makers, yet the analysis was conducted at a larger unit of observation. For example, many recent studies have found that a mild climate is associated with regional employment growth. The conclusion from these studies is that businesses want to open new plants in places where the climate is mild. The problem, however, is that the relationship may be totally spurious, and that climate may be related to other variables, such as levels of unionization, being considered by decision makers locating new plants. 


\subsubsection{Interpreting Results is Difficult}

Researchers sometimes are puzzled by the results of an econometric analysis. Energy costs, in particular, tend to be difficult to interpret. For instance, Cariton (1983) found that electricity prices were strongly related to the location of branch plants, even for an industry that was not electricity intensive. Carlton concludes that "the magnitude of the electricity price coefficient and even the sum of energy prices is surprisingly large relative to the wage coefficient based on aggregate industry shares in energy and labor shares in production. It is possible either that energy is acting as a proxy for prices of other inputs that are heavily energy dependent, or that the technology of new firms is such that they are more energy-intensive than existing firms in the industry" (p. 446). Thus, the results of Carlton's study actually generate more questions about the importance of electricity in choosing an industrial locetion.

\subsection{SURVEY FACTOR-RANEING METHOD}

The other major method of analyzing indus rial location decisions is the microbased approach using surveys. The following sections introduce the survey factor-ranking approach and discuss the advantages and disadvantages of its implementation.

\subsubsection{Description}

Many studies of industrial location rank the factors that are important to those who are choosing the location. These factors are then related to plant characteristics, and conclusions are drawn about which factors are most influential in decisions to locate certain types of plants or industries in particular locations. The ranking is drawn from direct surveys of key personnel who make the decision whether to locate new or expanded facilities in particular locations. Carefully designed questionnaires are sent to the decision makers, asking them to rank the factors that played a role in determining where to locate their facilities. The following text discusses the advantages and disadvantages of this method.

\subsubsection{Advantages}

Survey methods are very popular for these reasons: (1) data are obtained at the plant level, (2) the actual decision maker provides the information, (3) the researcher can learn about the interrelationships among location factors, (4) a weighting of all factors may be obtained, (5) the context of the location decision can be ascertained, and (6) results are easily interpreted.

\subsubsection{Plant-Level Data Are Used}

The survey method yields information about particular plants that is not attainable in macro-studies. This plant-level data can be a rich source of information for further analysis from which conclusions about plant behavior can be derived. In many 
macro analyses, researchers attempt to identify factors important in influencing the choice of plant location by using econometric techniques in cross-sectional studies. Whereas data availability is an advantage of econometric analysis, the form of the data severely restricts the researcher. In survey studies, the researcher does not speculate about plant activity on the basis of changes in employment or numbers of establishments; instead, the researcher gets direct information about plant opunings or closures.

\subsubsection{Conculsions about Individual Behavior Are Made Directly}

Perhaps the most compelling reason for the popularity of the survey method is that the survey goes directly to the person or persons involved in making the location decision. This direct approach allows the researcher to draw conclusions about the factors that plant managers or other decision makers actually used in making their location decision. The researcher does not infer the importance of factors on the basis of behavior.

By contrast, researchers using econometric methods report their results in terms of the significance of variables in their study. They may have difficulty linking the findings to plant location behavior. Part of the problem occurs when unexpected variables that are difficult to explain (or that are not consistent with currently accepted theory) appear to be significant. Other researchers create variables to provide a better fit to the data, and one never knows how many regressions were undertaken before the significant results were achieved. Some rscoarchers even confess that certain variables were significant "in early runs of the regressions."

At the more basic level, however, is the problem of using statistical approaches to explain individual behavior when the motives underlying individual decisions are unknown, or when methods of association are used to explain cause-and-effect relationships. Many macro econometric studies encounter difficulties in measuring variables (Bartels, Nicol, and Duijn 1982). As previously mentioned, the market variable in particular is very problematic. By contrast, in a survey study, the importance of markets and other factors can be directly ascertained.

When one conducts surveys, one can also gather specific information about the nature of the location search process by asking questions such as these: Was a search actually undertaken? Did the search process involve a multistate region? Were other localities considered and rejected? What led to the rejection of these other regions or localities?

\subsubsection{Factor Ratings Can Be Related to Other Variables}

Because the researcher goes directly to the person making the location decision, other relevant information about the firm or person can be ascertained, thereby providing a rich data bank for understanding location decisions. The researcher can then relate these location factors to the characteristics of the plant. Developing a plantspecific context based on these types of data can be important, because a location factor may be crucial to production-based branch plants but insignificant to other types of plants, such as new, single-plant establishments. 


\subsubsection{All Factors Are Evaluated}

The survey method allows the researcher to svaluate the contribution of many factors that may influence the location decision, not simply the principal factors. This capability can be important, given the of ten-times highly idiosyncratic way in which people make decisions. Sometimes the final choice of location is determined by what appear to be inconsequential factors, because the seemingly important location factors were considered initially, when candidate sites from which to choose were being identified. Survey studies with extensive lists of location factors are able to detect these seemingly minor influences, which may, in iact, be importarit. Since many locations may be equally attractive, the manager may decide upon the final location because of a seemingly minor personal factor that ultimately makes the selected site appealing (Schmenner 1982).

On the other hand, econometric methods are useful if one wishes to examine particular research questions, such as the impact of industrial parks on industrial location. Such studies allow the researcher to control for other variables and to evaluate the significance of the variable in question, which is userul in testing particular hypotheses. This type of testing is also necessary in many cases in which one is trying to evaluate the significance of public investments, such as infrastructure, which generally are factors that are not as significant as the traditional location factors.

\subsubsection{Context of Siting Decisions is Considered}

The survey approach also allows the researcher to consider the location decision within the larger context of making decisions to either start up a business or to expand capacity (Schmenner 1982). One may be able to determine whether the goal in locating the plant is to compete in new markets, expand production capacity, relocate existing production facilities, or introduce a new product line. Also, the decision maker's choice can be analyzed to determine if profit maximization, risk reduction, or some other goal was the primary motivation underlying the choice of location and the ratings of factors. For instance, a firm may locate in a state with a high labor cost because management's primary concern is not to minimize production costs but to expand into a new market.

Furthermore, if the questionnaire is properly designed, the researcher can distinguish between factors influencing the regional search and those important in selecting the locality. This information is important for public policymakers, who may need to know what factors are significant in making their state more attractive to industry, or who may wish to know how particular localities could become more competitive. The researcher can also determine how knowledgeable plant-location decision makers are about programs of fered by goverdment agencies. Kieschnick (1981, pp. 71-72) found that less than 20\% of business decision makers opening new firms were aware of incentive programs in the state in which they located a new business. For branch plants, tha percentage was higher, with about half of the decision makers interviewed being aware of state incentive programs. Such information can be useful to officials in publicizing their incentive programs or in modifying programs if they are not reaching their target audience. 


\subsubsection{Reporting and Interpreting Results Are Basy}

Survey results are easy to report and interpret. Depending on the nature of the survey, one can list factors in order of their importance, use the results in descriptive statistical analysis, or employ the results in econometric analyses to explain the choice of location. If interviews with decision makers are taken and recorded, the researcher can apply content analysis to rank location factors by their significance (Stafford 1985). No matter how information is collected, tables that rank factors as most important, important, or insignificant can be readily constructed. The factor ratings can also be used in a discriminant model to distinguish between categories of plants or searchers (Townroe 1985). Also, information collected from surveys (such as states considered in the search process) can be used in logit or probit models to test for the significance of factors in the choice of location (Schmenner, Huber, and Cook 1987).

\subsubsection{Disadvantages}

Despite the important advantages, the survey method has disadvantages. These include (1) the expense of survey research studies, (2) the frequent low response rate, (3) difficulty in contacting the correct persons, (4) responses from unauthorized individuals, (5) restriction by location or industry, (6) difficulty in obtaining comprehensive plant addresses, (7) sample censoring due to closures or relocations, and (8) respondent bias.

\subsubsection{Research Is Expensive}

Survey research projects are very expensive. As will be shown later, in both mail and telephone surveys, just obtaining a listing of plants to be contacted can be expensive in itself. In the case of mail questionnaire surveys, the survey instrument needs to be developed, copied, and then mailed with a cover letter and return postage. If the project is being funded by a federal agency, the questionnaire will also require Office of Management and Budget clearance before the study can begin. This clearance takes from three to six months, in addition to the time needed to prepare the statement -delays that add to cost. Once the questionnaire is mailed, follow-up postcards, letters, or telephone calls are necessary if the response rate is low. Furthermore, additional questionnaires must be mailed to those who did not return the original questionnaire. Finally, when the questionnaire is returned, the responses need to be coded and entered in to the computer for analysis.

Telephone surveys are equally expensive. A typical intervie's takes about 20 minutes once the correct person is identified and agrees to the interview. In addition to paying telephone bills, the researcher needs to pay for the services of interviewers. As was the case for mail surveys, responses need to be coded and entered into a computer for analysis. 


\subsubsection{Response Rate Can Be Poor}

Many industrial location surveys have poor response retes that can affect the degrees of freedom in statistical analysis. Unfortunately, many researchers fail to disclose this information in reporting their results. Generally, the response rates from small, single-plant establishments are higher than those from large multiplant firms, because in the former case the person who made the location decision is easier to contact and more likely to participate in the survey. With large multiplant firms, identifying the appropriate individual is of ten difficult because the questionnaire may arrive at the desk of a plant manager who was not involved in the location decision. The manager, in turn, may either send the questionnaire to the headquarters or discard it. Also, many larger firms have a policy of not responding to questionnaires for fear of disclosing information to competitors.

\subsubsection{Contacing the Appropriate Persons Can Be Difficult}

Often it is difficult to identify the person(s) involved in the location decision; this problem occurs more often for large multiplant firms but also occurs for small plants. The problem becomes more acute the tarther back in time the researcher goes when constructing the list of plants to include in the survey. When lists contain plants that were sited in the recent past, the likelihood of contacting those actually involyed in the location decision is increased. When lists contain older plants, however, managers unknowledgeable about the location decision may be contacted, since those who were involved in the decision may have left the company and the present managers do nct know the history of the plant's siting. In such cases, data may be unobtainable.

For a large firm, such as a Fortune $500 \mathrm{firm}$, contacting the correct individual can be extremely challenging. The firm may have delegated an office to handle decisions on locating new plants, management may have organized a committee to select a location, or the firm may have hired a locational consultant to recommend a location.

\subsubsection{Unauthorized Individuals May Respond}

If the questionnaire is sent to a department, it may be completed by individuals who were not involved in the location decision and who therefore respond based on their impressions of which factors were most important in determining the plant's location. In such cases, the researcher usually cannot evaluate whether the responses are accurate.

\subsubsection{Results May Be Location- or Industry-Specific}

Because survey studies are very expen ve, they need to be restricted by location or industrial sector. Of ten researchers will undertake a study of particular industries or of all firms in a small region. Thus, the results may be unique to the region or industry and not applicable to other regions or industries. Of ten, in a regional study, there is too much variability across industries to derive meaningful conclusions, and in a single industry study, regional factor variations may add complexity. 


\subsubsection{Ohtaining Comprehensive Plant Addresses Is Difficult}

As mentioned previously, there exists no comprehensive listing of manufacturing plants that can be used in industrial location survey research. Although County Business Pattems is generated from universe listings and is before not subject to sampling errors, it is subject to nonsampling errors, as pointed out in Halverson (1988). These include (1) the inability to obtain information about all cases, (2) derinitional and classification problems, (3) differences in interpretation of questions, and (4) errors in recording or coding the data. Unfortunately, it also does not provide names and addresses of firms, nor does it show the actual numbers of new plants sited (or closed) in a period.

As a result, the researcher needing a listing for a mailing or telephone survey must rely on the $D \& B$ Market Identifiers File and on state manufacturing directories. Dun and Bradstreet's minimum charge is approximately $\$ 2000$, and many of its records are not usable because they often include closed or relocated firms but do not include new branch plants. Although some state manufacturing directories appear to be comprehensive, many are not. Furthermore, not all state directories are available on disk or tape, and not all directories include the date when the plant was established -essential information for those interested in contacting recently established plants. In many states, companies must voluntarily submit the information that is included in the directory; thus, many companies simply do not submit information. In general, unless significant funding is available, one cannot attain a listing of plants, except perhaps for a single state study.

\subsubsection{Closed and Relocated Plants Are Not Surveyed}

Although one can survey existing plants, one cannot easily survey plants that have closed or relocated. A research project investigating locations over a period of time (e.g., 10 years) will actually be surveying surviving plants rather than all plants that were established. The characteristics of surviving plants are likely to be much different from the larger population of plants that would be considered if all plants that began operation over a time period were surveyed.

\subsubsection{Respondents' Answers May Be Biased}

Many studies provide respondents with a long list of factors that may have influenced the location decision. Given this listing, the respondent may check factors that actually were not important in the location decision but that the respondent believes are now important after operating in an area. As a result, the researcher may be led to conclude that many factors influenced the location decision, when in fact, few did. Also, the respondent may believe that answering the questionnaire in a certain way may favorably influence public policy. For instance, a respondent may cite the importance of nonunionized labor in a state in order to help keep unions out. Low taxes is another factor that respondents might cite so that state leaders will be influenced to believe that if taxes are raised, the state will not be able to attract new industry. 


\section{FINDINGS IN THE LITERATURE}

\subsection{RECENT ECONOMETRIC STUDIES}

Wasylenko (1988) summarizes the econometric studies on locating intermetropolitan manufacturing firm location in the United States. He reports the industry, unit of observation, data analyzed, and the significance of business climate variables for studies conducted by Carlton (1979, 1983), Plaut and Pluta (1983), Newman (1983), Bartik (1985), Benson and Johnson (1986), Wasylenko and Meguire (1985), Stutzer (1985), Helms (1985), Schmenner, Huber, and Cook (1987), Papke (1987), and Wasylenko (1988). Studies not reviewed by Wasylenko include Oster (1979), Walker and Calzonetti (1990), and Wheat (1986).

In separate studies, Carlton $(1979,1983)$ investigates the significance of factors influencing the birth of single-plant establishments and branch plants across SMSAs in the late 1960 s and early 1970s. He uses D\&B files to obtain the number of plants established in the SMSAs and their employment sizes, and he relates these to the attributes of the SMSAs. Using a conditional logit model developed by McFadden (1974), Carlton analyzes the location of plants among discrete alternatives. In this formulation, the probability that firm $i$ locates in region $j$ is a function of the firm's claracteristics (branch plant or single-plant establishment, industry, employment size) anit the region's attributes. Carlton restricts his investigation to the fabricated plastic products (SIC 3079), communication transmitting equipment (SIC 3662), and electronic components (SIC 3679 ) industries. Data on SMSAs include wages rates, corporate taxes, property taxes, personal income taxes, electricity costs, natural gas costs, agglomeration effects and birth potential, engineers, business climate, and unemployment rates.

In his 1979 study, Carlton found that wage rates exert a large and significant impact on the birth of single-establishment plants for SICs 3079 and 3662 , but wage rates are insignificant (although with the correct sign) for SIC 3679 (p. 34). For SICs 3079 and 3679 , energy costs are significantly related to new births, but energy is not significant for SICs 3662. Also significant are coefficients of agglomeration and technical expertise, as measured by number of engineers. For SICs 3662 and 3679 , the unemployment rate is significant and negatively related to new plant births. Carlton concludes that these findings mean that local economic conditions can influence the birth of new manufacturing plants, but tax variables are not significant. With regard to branch plants, energy costs and local economic conditions exert a strong influence on the birth of new plants, but tax variables are not signif'icant.

Bartik (1985) also uses a conditional logit formulation in examining the decision to open a branch plant in a state. Bartik corrects for two problems with the econometric method: the "implausibility of the independence-of-irrelevant alternatives" assumption, and the use of areas (such as SMSAs) as the units of observations (1985, p. 14). Bartik uses micro-level data collected by Schmenner for Fortune 500 companies that located new plants in the United States. Schmenner purchased D\&B files for 1972 and 1978 , compared the listings to identify possible plant openings and closures, and contacted the companies for verification (Bartik 1985). Independent variables in Bartik's analysis include land area, unionization, taxes, unemployment and workers compensation, road 
miles, manufacturing activity, education, construction costs, population density, energy prices, and work stoppages.

Bartik concludes that unionization has an extremely strong negative impact on business location. Also, state corporate taxes appear to negatively influence the likelihood of a branch plant being opened in a state. This finding contradicts many cther studies that show no relationship between such taxes and industry location (Carlton 1979, 1983). In addition, existing manufacturing activity and the number of road miles have a strong effect on new business location. However, Bartik does not find energy prices and wages to have a statistically significant impact on new branch plant location in the preferred specification of the model.

Wheat conducted two nationwide studies examining the importance of factors contributing to growth in state manufacturing employment. In his earlier study (Wheat 1973), the leading determinants of state manufacturing growth from 1947 to 1963 were found to be markets, climate, labor, thresholds, resources, and urban attraction. The threshold variable captures the fact that iive western states lack an adequate developmental base to cross the threshold leading to faster growth. in this study, markets were the dominant locational factor.

Wheat (1986) replicated this study for the period 1963 to 1977 in his evaluation of 10 factors contributing to the percent change in manufacturing employment in the 48 contiguous states. He found that six factors were significant, in the following order: markets, climate, labor, tizresholds, rural attraction, and retirees. In a multiple regression model, these factcrs proved to have a very high explanatory power. The retirees variable is used by Wheat as a surrogate for amenities on the assumption that retiree counties "are almost all characterized by lakes, seacoasts, or mountains" (Wheat, 1986). In contrast to his earlier study, Wheat finds in this study that rural attraction is the third most important factor. He is hesitant in his explanation of this variable, suggesting that it could represent the in-migration to rural states, which creates a growth in manufacturing and agricultural industries and attracts noncompetitive labor markets - all of which are consequences of the product-life theory, or the growing aversion to cities. These ambiguous findings demonstrate the limitations of the econometric method.

Plaut and Pluta (1983) also conducted a nationwide study to identify factors contributing to growth across states from 1967 to 1977. They use four groups of dependent variables (markets, factors of production, environment and climate, and state business climate) on three measures of industrial growth (percent change in real value added, percent change in employment, and percent change in real capital stock) in multiple regression models. The models are successful in explaining from about one-half to three-quarters of the variance in the growth measures. Plaut and Pluta find that growth in industrial output (measured in terms of value-added) is strongly related to energy, labor factors, land, and climate; percent change in employment is related to climate, labor factors, business climate, taxes, and government expenditures; and percent change in real capital stock is related to energy, land, markets, business climate, taxes, and government expenditures. 
Plaut and Pluta conclude that the traditional location factors still explain most of the changes in industrial growth across states, although the importance of markets is not as strong as expected. This finding could be a result of the weakness of the market varlable used by the authors and explained previously. Energy prices and avallability were somewhat important variables and were a "major determinant of output and capital stock growth, but relatively minor determinants of employment growth across states." They conclude that energy has become a much more important variable in explaining regional industrial growth patterns since the 1973 Arab oil embargo.

Newman (1983) tests three hypotheses regarding industrial growth in the southern states: Is the growth explained by differentials in state and local taxing policies, the degree of unionization, or buisiness climate (as measured by a right-to-work law)? Using macro-level data for 13 two-digit manufacturing SIC codes for which these independent variables are regressed on ehanges in industry growth by state, Newman concludes that corporate tax rate differentials, unionization, and business climate affect industry migration to the South. Furthermore, taxes and right-to-work laws not only affect migration to the South, but also affect migration within the South.

Oster (1979), instead of evaluating the attributes of factors important in the selection of a location, more directly examines the factors related to the likelihood that a firm would undertake a search. She concludes that a firm is more iikely to search if it uses more inputs that display greater regional price variation. However, this conclusion rests upon a measure of labor intensiveness of unskilled workers. The search process is also evaiuated by Schmenner, Huber, and Cook (1987), who consider the regional search and secondary search for Fortune $500 \mathrm{firms}$. This study is discussed in the next section.

A recent study examining that search process in more detail is grovided by Walker and Calzonetti (1990), who investigate new plants established in West Virginia and eastern Kentucky since 1972. Plant managers were questioned about their location search as well as about the cost of inputs in their production process. Examining the regional and local search process, Walker and Calzonetti find that a discriminant model is successful in distinguishing between searchers and nonsearchers for branch plants only. For the regional search, the einployment size of the plant and energy intensity are significant. This study region (West Virginia and eastern Kentucky) has the least expensive electricity costs east of the Mississippi. For the local search, only transportation is a significant factor. As will be discussed later, many factor-ranking studies indicate that proximity to highways is an important consideration in the local search for manufacturing plants.

In other studies, Benson and Johnson (1986) in a study across the 48 states, regress the per-capital annual expenditure on manufacturing plant and equipment on wages, welf are expenditures, state and local debt to personal income, and state and local taxes to personal income. Their results indicate that taxes are an important determinant of expenditures on manufacturing plant and equipment in states that suppress investment in manufacturing. Stutzer (1985) finds that small-issue industrial revenue bonds are not significant in explaining state employment growth. Finally, as summarized by Wasylenko (1988), Wasylenko and McGuire (1989) analyze total employment growth in the United States over the 1973-1980 period for six industries. They find that wages, energy prices, and per-capita income are important determinants of employment growth. The state 
personal income tax rate has a negative impact on employment growth in the wholesale trade, retail trade, and finance industries, whereas education expenditures have positive effects on employment growth for the retail trade and finance industries.

\subsection{SURVEY FACTOR-RANKING STUDIES}

This section reviews the findings brought forth in numerous major studies that used the survey factor-ranking method. The studies reviewed include early efforts on this topic to the most recent endeavors. It is evident from these studies that traditional factors still dominate the decision-making process; however, "softer issues," such as public attitudes and regional amenities, are gaining in importance.

Morgan (1967) provides a good review of 24 early survey studies conducted mostly during the $1940 \mathrm{~s}, 1950 \mathrm{~s}$, and the first half of the $1960 \mathrm{~s}$ as part of his study of the importance of taxes and inducements on the locstion of industry. Seventeen of the studies reviewed involved questionnaires and seven involved interviews. Most of the studies were conducted by state organizations, generally the bureaus of business research at the state universities, and focused on new plants locating in the state. The response rate for most of the earlier studies, particularly those conducted for specific states, was very high.

Table 1, which summarizes the ratings for the questionnaire and interview studies, shows that the traditional location factors (i.e., markets, labor, and raw materials) were the dominant reasons identified by the manufacturers. Almost all of the studies rated markets (i.e., market proximity) as the most important location factor. Taxes and financial inducements were not rated very high in these early studies. Morgan (p. 14) observed that because none of the studies distinguished between the selection of the region of interest and the selection of the plant sice, the results are obscured. This weakness of early studies was also recognized by Mcl!illan (1965), who argued that the determinants of plant location becorne important only when the plant locator is comparing localities. McMillan reported the results of a McGraw-Hill survey that asked managers of existing plants about the desirable characteristics of a site for a new plant. Trucking, land costs, reasonable or low taxes, favorable labor climate, and favorable attitude toward business were the factors most of ten cited. However, it is worth noting that these findings are based on the assumption that the location of a branch plant is being made and that regional factors are ignored.

A recent review of studies examining the factors influencing industrial location decisions is provided by Blair and Premus (1987), who review studies by Fortune, Inc. (1977), Kieschnick (1981), Schmenner (1980), Goldstein (1985), Hekman (1982), INC. Magazine (1980), Rees (1979), and Premus (1982). Most of the earlier studies were restricted by location (focusing upon a particular state or region), and they of ten did not distinguish among the different stages of the decision process by which a geographic location for a company is chosen. The emphasis of more recent studies has been on selected industries (e.g., high technology industry), size categories (e.g., Fortune 500 firms), organizational categories, selected policy variables and regulations, or particular factors. Researchers have also been clarifying some of the factors in recent studies and paying more attention to quality-of-life or environmental factors. For instance, the 
TABLE 1 Significance of Location Factors According to Questionnaire and Interview Surveys

\begin{tabular}{|c|c|c|c|c|c|c|}
\hline \multirow[b]{2}{*}{ Factor } & \multicolumn{3}{|c|}{$\begin{array}{l}\text { Significance } \\
\text { Accozding to } \\
\text { Questionnaires }\end{array}$} & \multicolumn{3}{|c|}{$\begin{array}{c}\text { Significance } \\
\text { According to } \\
\text { Interviews }\end{array}$} \\
\hline & Primary & Some & Little & Primary & Some & Litcle \\
\hline Markets & 16 & 1 & - & 6 & 1 & - \\
\hline Labor & 10 & 7 & - & 3 & 4 & - \\
\hline Raw materials & 10 & 6 & - & 3 & 4 & - \\
\hline Transportation & 7 & 10 & - & - & 6 & - \\
\hline Taxes & 1 & 3 & 13 & - & - & 1 \\
\hline Financial & - & - & 13 & - & 0 & 7 \\
\hline
\end{tabular}

Source: Morgan (1967).

variable is now often subdivided into wage rates, labor productivity, and unionization. Quality of life is now recognized as an important factor in hiring and maintaining a highly educated and mobile work force for many industries.

In some studies of particular states or regions, the research question restricts the geographic scope of the study. Kieschnick, for example, who was interested in the role of business incentives on industry location, surveyed firms in only the 12 states that sutomatically of fer investment or amployment incentives.

Blair and Premus observe that the traditional location factors, found to be most significant in the review undertaken by Morgan in the 1960s, were also significant in recent surveys, but that "softer issues," such as attitudes toward business, were growing in significance. In his survey of 691 high-tech company executives, Premus (1982) found that the availability of technical labor and the cost of labor are major considerations, followed by proximity to a university system and by taxes. Attributes of the community were also considered important, whereas raw materials, energy, climate, and transportation of goods were not rated highly (Blair and Premus, 1987, p. 79).

Possibly the most comprehensive work in recent years has been conducted by Schmenner. In addition to using large surveys, Schmenner has distinguished between the regional and local search. In his study of firms locating in Cincinnati and New England, Schmenner (1978) fnind that proximity to markets was the most important factor in the regional search for $71 \%$ of the Cincinnati firms and $51 \%$ of the New England firms. Schmenner's Fortune 500 study found that favorable labor climate was the most. important factor, followed by proximity to markets (Schmenner 1982). In a later study, Schmenner, Huber, and Cook (1987) used both micro-and macro-data in a two-stage logit model to identify the factors that were significant to large companies that considered more than one state as they were choosing where to locate 114 new plants. In the first 
stage, in which the plant manager identifies a few states of interest, lower labor union activity, lower bullding costs, warmer climates, and lower population densities were found to be significant factors. It was much more difficult to explain the cholce in the second stage of the location decision. The results, however, do support the view that when branch plants are sited, consideration is given to unionization and other physical and socioeconomic attributes of states.

The above studies suggest that traditional factors still play a role in location dec:sions, particularly when one distinguishes among the plant location decisions for new firms, branch plants, and firms expanding capacity on site. The literature shows that for manufacturers in general, labor-related factors are still extremely inportant in choosing locations for branch plants and that market factors are important in choosing locations for single-plant establishments. For example, Hake, Ploch, and Fox (1985), in a mail questionnaire study of 325 firms in Tennessee that opened between 1980 and 1.983 , compare the importance of factors across different types of plants. For new establishments, access to markets was the highest rated factor, followed by a desire to avoid unions. For branch plants, the desire to avoid unions and locate in a pro-business state dominated, supporting the findings of Schmenner, Huber, and Cook (1987). For those firms that considered other states before locating in Tennessee, the top three factors were (1) less union influence, (2) right-to-work laws, and (3) pro-business attitudes of state government. Labor was also the highest-rated factor in a survey of manufacturing firm presidents who located or considered locating in Arkansas, another sunbelt state (Epping and Napier 1984). Taxes followed labor as the second most important factor for firms that located in Arkansas and for firms that consiciered Arkansas but located elsewhere.

The persistent importance of labor is shown in studies at the national level. Kieschnick (1981) found that market factors were particularly important for new singleplant establishments, but the most important factors for branch plants were labor supply and unionization. However, kieschnick obtained responses from only 32 brarich plants in his study. Stafford (1985), who reported the results of 54 interviews with executives and 104 mail questionnaires, found that labor was most important consideration for branch plants in local searches for new plant sites. At the national and regional levels, the market factor was most important factor, according to Stafford.

Labor has also been shown to be important in a state with traditionally strong labor unions. In a study in which 406 Michigan plant managers were asked about the factors they would look for if they wanted to expand or relocate, Schmitt, Marcus, Gleason, and Pigozzi (1985) found that manufacturers would look for areas with high worker productivity, good labor relations, low cost of workers compensation, and low wages.

Thus, it appears that although personal and "softer issues" are more important now than in the past, there is still evidence that the traditional factors play a significant role in the location of manufacturing plants. However, most of the more recent studies have been restricted by location, industry, or firm type, and thus it is difficult to draw general conclusions. In the following section, results of a recent nationwide survey are explored, with particular attention given to the western states. 


\section{FACTORS INFLUENCING INDUSTRIAL LOCATION IN 'THE WESTERN STATES}

A very recent study conducted by West Virginia University (WVU) allows for a regional breakdown of results.* This study, funded by the Economic Development Administration, is a nationwide survey of new manufacturing plants that have started operations since 1978. It covers all industries and includes new plants with five or more employees. Two sources were used to obtuin the listing of plants: the D\&B Market Identifiers File and selected state manufacturing directories. The D\&B file was used to obtain listings for new plants nationally, since state manufacturing directories do not provide complete national coverage. A simple random sample of 2710 new manufacturing plants that began operarion since 1978 was drawn from the Market Identifiers File. Although this file has been acclaimed as a virtual census of U.S. businesses (Struyk 1972; Malecki 1985), our experience has been similar to those who have found the file inadequate in many respects (Schmenner 1982; Schwartz 1987). In addition to the plants obtained from the Market ldentifiers File, 10\%-stratified random samples were drawn from 28 manufacturing directories.

A mail questionnaire survey was designed by WVU researchers and the Economic Development Administration contract officer. This questionnaire contained sections on the characteristics of the plant and firm, factors influencing the regional search, factors influencing the local search, and the importance of electricity as a factor in the location decision. A regional search is described as the selection of one state or a multistate area before specific localities are considered. A local search is described as the selection of a specific town, metropolitan area, or other locality for a new plant. Respondents were asked to indicate the importance of location factors for separate lists of regional and local factors. A follow-up postcard was mailed to those who did not respond to the initial mailing, and if no response was forthcoming, telephone surveys were conducted. As of September 1988, 739 questionnaires were returned completed, coded, and filed. The following discussion uses these responses as its basis.

First, this report provides a summary of rankings of regional factors given by respondents who sited their manufacturing plant after a regional search was conducted. Nationwide totals are used. Next this report considers the factors important in a local search. Finally, the rankings of local factors are compared for the Mountain States, Midwest, and Southeast. Mountain states include Arizona, Colorado, Idaho, Montana, New Mexico, Nevada, Utah, and Wyoming. Midwestern states include Illinois, Indiana, Michigan, Ohio, and Wisconsin. Southeastern (South Atlantic) states include Alabama, the District of Columbia, Delaware, Florida, Georgia, Maryland, North Carolina, Virginia, and West Virginia.

\footnotetext{
* Because no report has been prepared for the WVU study, the raw dpta results were used for preparing this section.
} 


\subsection{REGIONAL SEARCH}

Of the 739 respondents, 174 (23.5\%) conducted a search across regions when selecting a site for their new manufacturing plant. Table 2 summarizes the rankings of the location factors for all plants, single-plant establishments, and branch plants. The table summarizes the frequencies for those who replied that a particular factor was either the "single most important" factor or a "very important" factor in their selection of a general region of the country before they chose a particular locality within that region.

Markets and labor were tied as being the top two factors for all plants, with 110 responses each. However, 53 respondents said that markets were the single most important factor, and 31 respondents elaimed that labor was the single most important factor. Land and taxes were rated as the third and fourth most important factors. Only 8 respondents said that land was the single most important factor, and 5 respondents said that taxes were most important. The remaining factors, in order of importance, are personal reasons, education, resources, nontax incentives, electricity prices, and proximity to suppliers. Many respondents listed personal reasons or resources as the single most important factor. It is expected that certain manufacturers are tied to particular resources and must have access to these resources. Although land, taxes, and education had high combined scores, few manufacturers said that these factors were the single most important factor, which indicates that even though these are desirable characteristics, they are not absolutely necessary.

Single-plant establishments and branch plants rank markets and labor as the top two factors. In both cases, the combined scores are equal, but many more respondents said that markets were the single most important factor. For single-plant establishments, land was the third-ranked factor, followed by personal reasons, taxes, resources, proximity to suppliers, electricity, education, and amenities. Personal reasons are much more important to single-plant establishments, where this factor is rated fourth, than to branch plants, where the factor is rated tenth. Taxes were rated third by branch plants but fifth by single-plant establishments. It is also interesting that managers of branch plants rated education as being more important than did managers of single-plant establishments. The importance of the availability of an educated work force was also found by Wasylenko (1988) to be positively related to manufacturing empleyment growth.

In summary, these results incicate that the traditional location factors (markets, labor, land, taxes) are still dominant. Resources aie not listed among the top factors but are of secondary importance to many plants. Table 2 reveals few surprises in light of what is already known about factors influencing industrial location decisions.

\subsection{LOCAL SEARCH}

Table 3 summarizes the rankings of plants that undertook a local search. There is some difference between the rankings of factors for single-plant establishments and branch plants. ivarkets are the inajü factor foi single-plant estahlishments, followed by highways, nonunion labor, and vacant sites. For branch plants, nonunion labor scored 


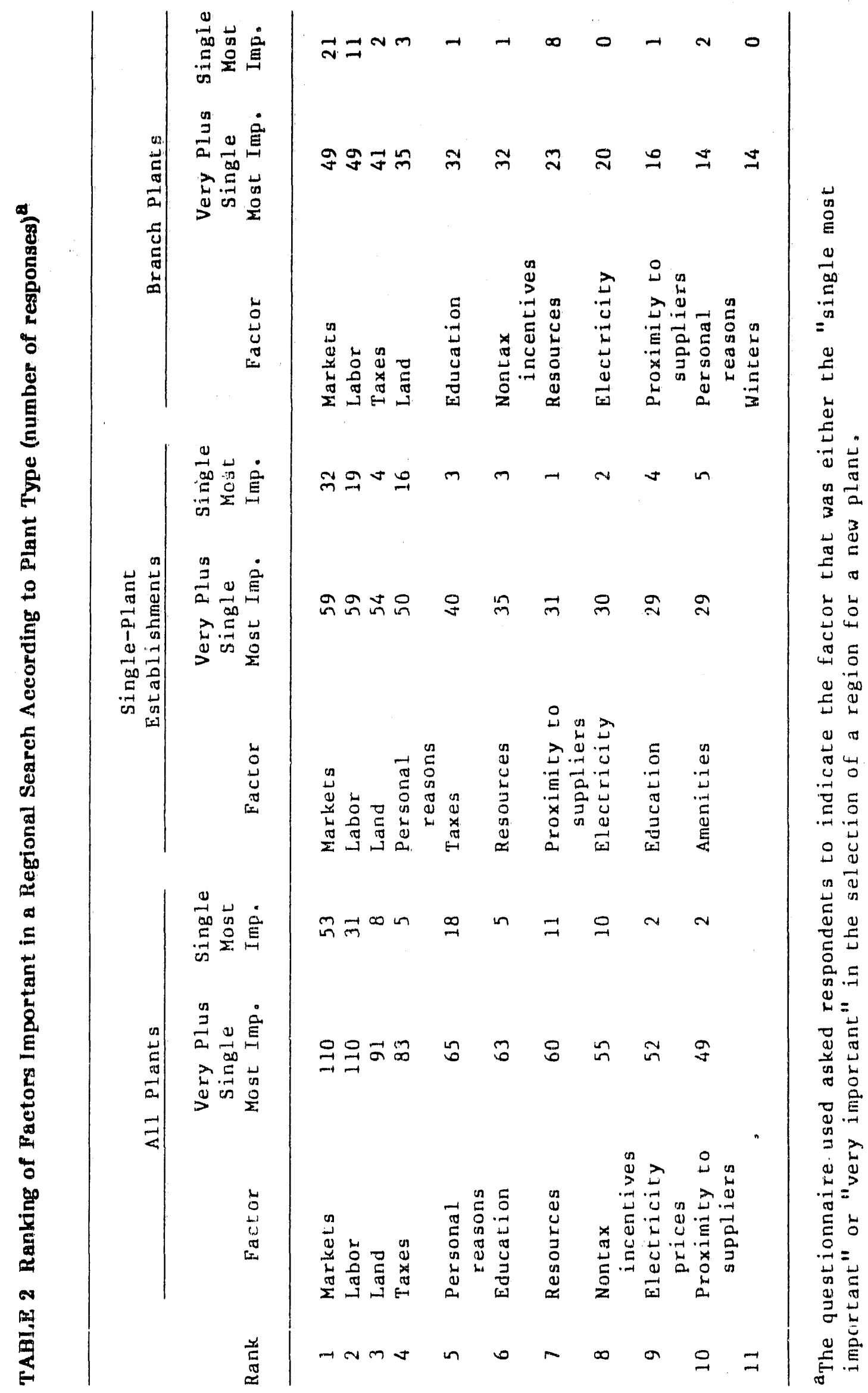




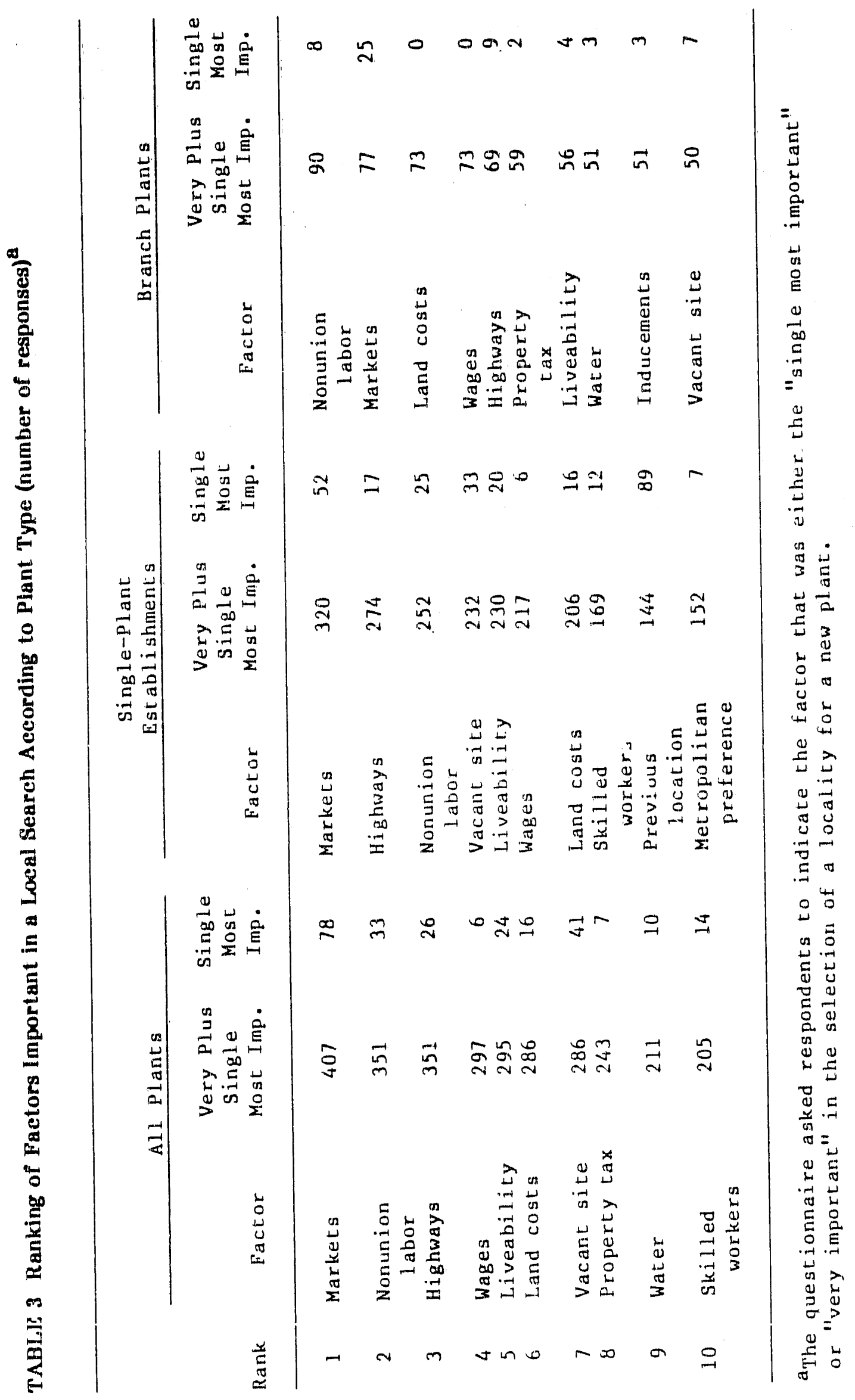


highest, but more respondents regarded markets as the single most important factor than any other factor. Land costs and wages were also highly rated by branch plants. Three of the top four factors cited by branch plants were cost-related factors. The availability of a vacant plant or shell building was rated highly by single-plant establishments but was not rated as important by branch plants. Also, inducements did not seem to play an important role either for single-plant establishments or for branch plants in their selection of a locality for their new plant.

Table 4 compares the rankings for various attributes of a locality given by managers of single-plant establishments in the Mountain, Midwest, and South Atlantic regions of the United States when deciding whether to open a new plant. The presence of nonunion labor was most important to managers in the Midwest and South Atlantic, but markets and highways were rated most highly by managers in the Mountain States. Liveability was also highly rated in the Mountain States when compared with the other two regions. 


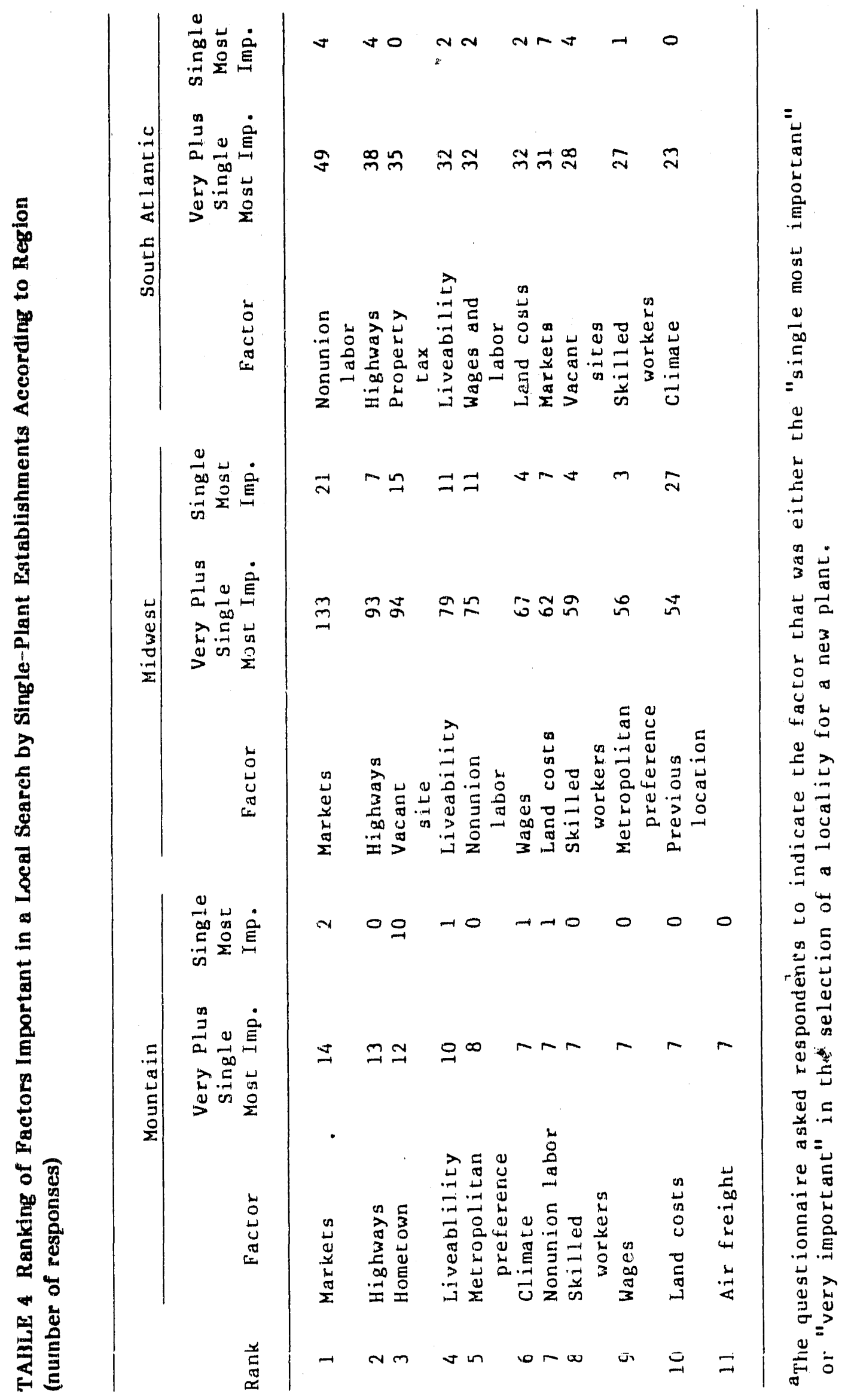




\section{IMPLICATIONS FOR RESEARCH ON PERCEPTION-BASED IMPACTS}

This report has provided a general background on state-of-the-art methods for determining the importance of regional factors in industrial location decision making. Econometric and survey-based factor-ranking methods have been described, and major findings from a review of the literature on studies that used these methods have been presented. It is evident that not much research has been conducted to show whether perceptions of a region or area are important factors that are considered when industrial location decisions are made in the United States. There may be two explanations for the absence of perceptions as a potential factor. First, public perceptions about a region may actually not be a significant factor in the selection of a location for a new manufacturing facility. The other possibility is that they may indeed be a factor, but studies to date have not brought that fact to light. For example, if the factor has been important, it probably affects only a small number of establishments. Thus, the factor's significance or insignificance can not be discerned through macro-studies. Furthermore, the perceptions associated with noxious facilities in a region are iikely to be important at the local search level but not at the regional search level. Cross-sectional studies that use a state as the geographic unit of observation would not be likely to reveal that a local variable influenced either a location decision or the distribution of manufacturing activity. Another point is that researchers may not have designed their studies to test whether perceptions about noxious facilities are important in a location decision. Although studies can be designed to test for the significance of minor factors that contribute to a location decision, it appears that the perceptions about noxious facilities have not yet been investigated in industrial location literature.

Although factor-ranking studies have not found that public perception is a factor that influences location decisions, they do demonstrate that amenities or personal reasons are very important in many cases, particularly at the local level for single-plant establishments: Researchers have been clarifying some of these factors in recent studies and are paying more attention to quality-of-life and environmental factors. Quality of life is now recognized as an important factor for many industries in hiring and maintaining a highly educated and mobile work force. Thus, business people are concerned about the desiraole characteristics of locations in which to open a plant.

Recent results do support the view that branch plants are sited with consideration given to unionization and other physical and socioeconomic attributes of states. Results from the WVU survey show that western regions are of ten considered for the amenities they offer to a work force. If the nuisance factor associated with a large hazardous facility located in the region overpowers the positive amenities of the area, the location decision could be affected.

A major problem in determining the importance that public perceptions may have played in industrial location decisions is the difficulty of obtaining information about locations that have been rejected for specific reasons. In some studies, such as the one conducted by Schmenner, Huber, and Cook (1987), respondents were asked to list areas rejected in their search. For the most part, however, very little information has been collected about rejected locations. Future studies examining this issue may find that the concern about noxious facilities is a factor in the decision against a particular site. However, at present, nu eviuence is presentiy available to support such a hypothesis. 


\section{REFERENCES}

Bartels, C.P.A., W.R. Nicol, and J.J. van Duijn, 1982, Estimating the Impact of Regional Policy: A Review of Applied Research Methods, Regional Science and Urban Economics, 12:3-41.

Bartik, T., 1985, Business Location Decisions in the U.S.: Estimates of the Effect of Unionization, Taxes and Other Characteristics of States, J. of Business and Economic Statistics, 3:14-22.

Benson, B., and R. Johnson, 1986, The Lagged Impact of State and Local Taxes on Economic Activity and Political Behavior, Economic Inquiry, 24:389-401, July.

Blair, J.P., and R. Premus, 1987, Major Factors in Industrial Location: A Review, Economic Development Quarterly, 1:72-85.

Carlton, D.W., 1983, The Location and Employment Choices of New Firms: An Econometric Model with Discrete and Continuous Endogenous Variables, The Review of Economies and Statistics, 65: 440-449.

Carlton, D.W., 1979, Why New Firms Locate Where They Do: An Econometric Model, in W. Wheaton, ed., Interregional Movements and Regional Growth, The Urban Institute, Washington, D.C.

CBER, 1985, An Economic Analysis of Monitored Retrieveable Storage Site for Tennessee, Center for Business and Economic Research, University of Tennessee Press, Knoxville, Dec.

Epping, G.M., and H.S. Napier, 1984, Plant Location: A Conflict between Manufacturers and Community Interest Groups, Arkansas Business and Economic Review, 17:1-8.

Fortune Inc., 1977, Facility Location Decisions, Fortune Inc., New York City.

Goldstein, M.l., 1985, Choosing the Right Site, Industry Week, 15:57-60.

Greenhut, M.L., 1956, Plant Location in Theory and Practice, University of North Carolina Press, Chapel Hill.

Hake, D., D.R. Ploch, and W.F. Fox, 1985, Business Location Determinants in Tennessee, Center for Business and Economic Research, University of Tennessee Press, Knoxville.

Halverson, J., 1988, An Evaluation of Data Sources Used for Industrial Research, master's thesis, University of West Virginia, Morgantown.

Hekman, J.S., 1982, Survey of Location Decisions in the South, Economic Review, pp. $6-19$.

Helms, J.L, 1985, The Effects of State and Local Taxes on Economic Growth: A Time Series-Cross Section Approach, Review of Economies and Statistics, 36:83-94, Mareh.

Hemphill, R.C., et al., 1990, unpublished information, Argonne National Laboratory. 
INC. Magazine, 1980, Buildings and Site Selection, reader survey, Long Island, N.Y., p. 40 .

Kieschnick, M., 1981, Taxes and Growth: Business Incentives and Economic Development, Council of State Planning Agencles, Washington, D.C.

Malecki, E.J., 1985, Industrial Location and Corporate Organization in High Technology Industries, Economlc Geography, 61:345-369.

McFadden, D., 1974, Conditional Logit Analysis of Qualitative Choice Behavior, in P. Zarembkal, ed., Frortiers in Econometrics, Academic Press, New York City, pp. 105142.

McMillan, T..E., Jr., 1965, Why Manufacturers Choose Plant Locations vs. Determinants of Plant Locations, Land Economics, 41:239-246.

Morgan, W.E., 1967, Taxes and the Location of Industry, University of Colorado Press, Boulder.

Mountain West Research, 1989, Yucca Mountain Socioeconomic Project: An interim Report on the State of Nevada Socieconomic Studies, State of Nevada Agency for Nuclear Projects/Nuclear Waste Project Office Report NWPO-SE-022-89, Las Vegas, June.

Newman, R.J., 1983, Industry Location of Growth in the South, Review of Economics and Statisties, ô $5: 76: 86$.

Oster, S., 1979, Industrial Search for New Locations: An Empirical Analysis, The Review of Economics and Statistics, 51:288-92.

Papke, L., 1987, Subnational Taxation and Capital Mobility: Estimates of Tax-Price Elasticities, National Tax J., 40:191-204, June.

Plaut, T.R., and J.E. Pluta, 1983, Businesa Climate, Taxes and Expenditures, and State Industrial Growth in the United States, Southern Economic J., 50:99-119.

Premus, R., 1982, Location of High Technology Firms and Regional Economic Development, print from U.S. Congress Joint Economic Commiilee, Washington, D.C.

Rees, J., 1979, Regional Industrial Shift in the U.S. and the Internal Generation of Manufacturing Growth Centers in the Southwest, in W. Wheaton, ed., Interregional Movements and Regional Growth, The Urban Institute, Washington, D.C.

Schmenner, R.W., 1978, The Manufacturing Location Decision: Evidence from Cincinnati and New England, U.S. Economic Development Administration, Washington, D.C.

Schmenner, R.W., 1980, The Location Decision of Large Multi-Plant Companies, Department of Housing and Urban Development, Washington, D.C.

Schmenner, R.W., 1982, Making Business Location Decisions, Prentice-Hall, Inc., Englewood Cliffs, N.J.

Schmenner, R.W., J.C. Huber, and R.L. Cook, 1987, Geographic Differences and the Location of New Manufacturing Facilities, J. of Urban Economics, 21:83-104. 
Sohmitt, N., et al., 1985, How Business Leaders View Plans for Plant Expansion and Relocation, The Michigan Economy, 4:1-8, July-Aug.

Schwartz, A., 1987, Dun and Bradstreet's Market Identifiers and Economic Geography, The Professional Geographer, 39:166 172.

Smith, D.M., 1966, A Theoretical Framework for Geographical Studies of Industrial Location, Economic Geography, 42:95-113.

Smith, D.M., 1981, Industrial Location: An Economic Geographical Analysis, 2nd Ed., John Wiley and Sons, New York City.

Stafford, H.A., 1985, Environmental Protection and Industrial Location, Annals of the Association of American Geographers, 75:227-240.

Stutzer, M.J., 1985, The Statewide Economic Impact of Small-Issue Industrial Revenue Bonds, Quarterly Review of the Federal Reserve Bark of Minneapolis, pp. 2-13, spring.

Struyk, R.J., 1972, Evidence on the Locational Activity of Manufacturing Industries in Metropolitan Areas, Land Economics, 48:377-382.

Townroe, P.M., 1985, A Discriminant Analysis of the 1980 Sao Paulo Industrial Location Survey, Environment and Planning, 17:115-131.

Walkel, R.T., and F.J. Calzonetti, 1990, Searching for Vew Manufacturing Plant Locations: A Study of Location Decisions in Central Appalachia, Regional Studies, $24: 15-30$.

Wasylenko, M., 1988, Empirical Evidence of Inter-Regional Business Location Decisions and the Role of Fiscal incentives in Économic Development, paper presented at the Symposium on Industry Location and Public Policy, University of Tennessee, Knoxville, April.

Wasylenko, M., and T. MeGuire, 1985, Jobs and Taxes: The Effects of Business Climate on States' Employment Growth Rates, National Tax J., 38:477-511.

Weber, A., 1990, Alfred Weber's Theory of the Location of Industries, translated by C. J. Friedrich from Uber den Standurt der Industrien (1929), Unlversity of Chicago Press.

Wheat, L.F., 1973, Regional Growth and Industrial Location: An Empirical Viewpoint, D.C. Heath, Lexington, Mass.

Wheat, L.F., 1986, The Determinants of 1963-77 Regional Manufacturing Growth: Why the South and West Grow, J. of Regional Science, 26:635-658. 

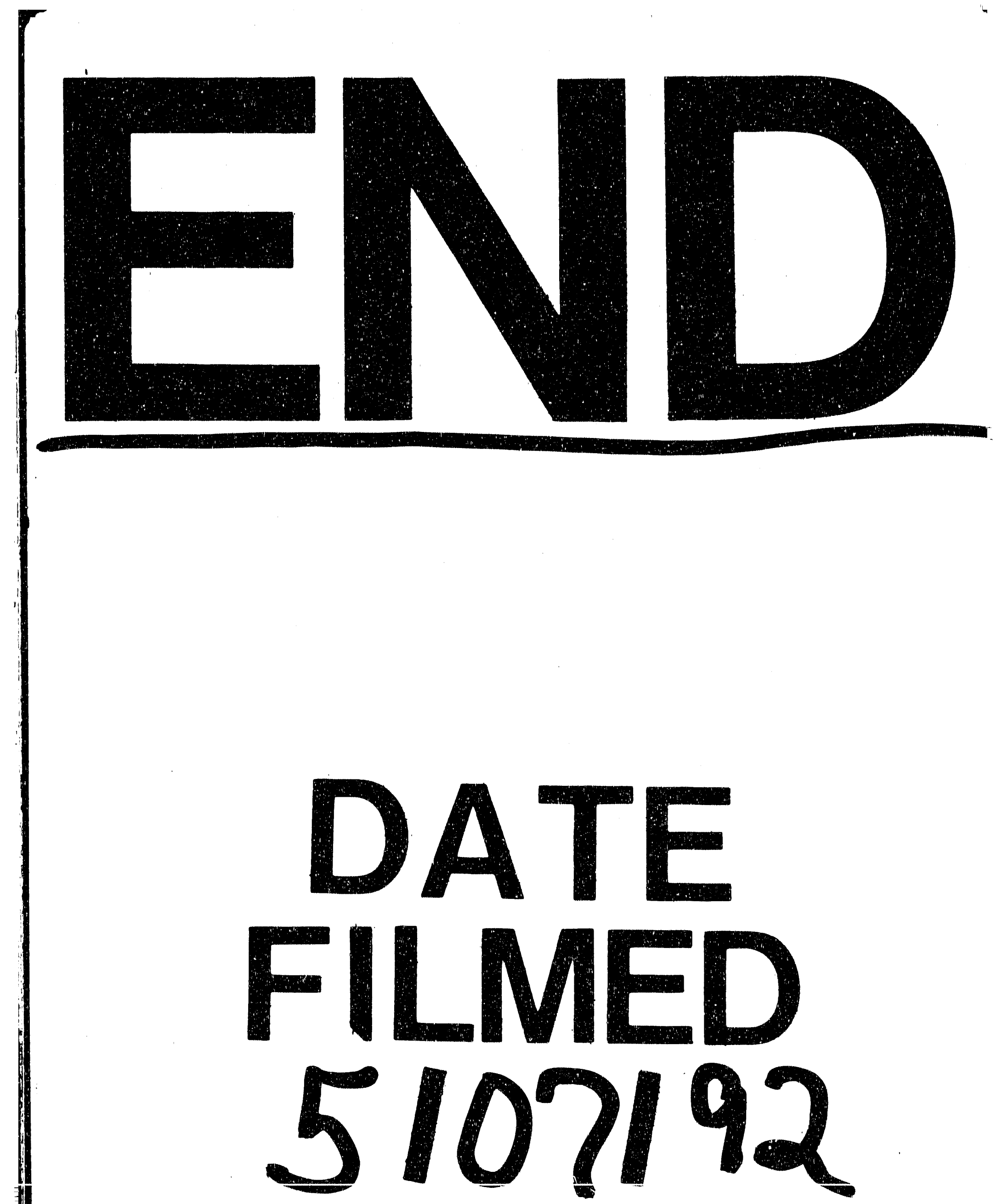


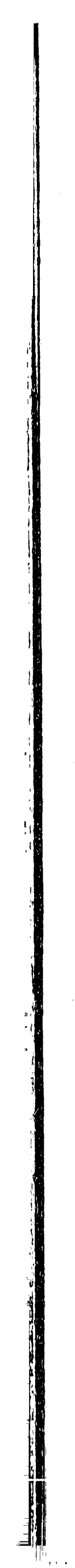

